\title{
Enhanced production of butyric acid by solid-state fermentation of rice polishings by a mutant strain of Clostridium tyrobutyricum
}

\author{
Tasleem Akhtar ${ }^{1}$, Abu Saeed Hashmi ${ }^{1}$, Muhammad Tayyab ${ }^{1}$, Aftab Ahmed \\ Anjum $^{2}$, Shagufta Saeed ${ }^{1}$ \\ ${ }_{1}^{1}$ Institute of Biochemistry and Biotechnology, ${ }^{2}$ Department of Microbiology, University of Veterinary and Animal Science, \\ Lahore, Pakistan \\ *For correspondence: Email: tasleem_ak@yahoo.com; Tel: +92-321-5874191, +92-3364988119, +92-544-656143
}

\begin{abstract}
Purpose: To enhance butyric acid production by solid-state fermentation with a hyper-producing mutant of Clostridium tyrobutyricum generated by random mutagenesis.

Methods: Wild type C. tyrobutyricum was mutagenized with UV irradiation, nitrous acid, and ethidium bromide to obtain a hyper-producing strain. Various physiochemical parameters were optimized to increase the butyric acid yield.

Results: The UV-induced mutant (C. $T^{U V}$ ) produced significantly higher concentrations of butyric acid than the wild type parent, nitrous acid-induced, and ethidium bromide-induced strains. C.T $T^{U V}$ increased butyric acid production 1.4-fold more than the parent strain. Fermentation with C. $T^{u V}$ with $2.5 \mathrm{~g}$ of rice polishings $(w / w)$, a $2 \%$ inoculum volume $(v / v)$, and a 48 - $h$ incubation period at $37^{\circ} \mathrm{C}$ under anaerobic conditions produced $11.63 \mathrm{mg} / 100 \mathrm{~g}$ of butyric acid. The addition of $0.6 \%$ corn steep liquor as a nitrogen source increased the butyric acid concentration to $26.09 \mathrm{mg} / 100 \mathrm{~g}$.

Conclusion: These optimized fermentation parameters on a small scale can be used on a commercial scale to mass-produce butyric acid.
\end{abstract}

Keywords: Butyric acid, Mutant, Clostridium tyrobutyricum, Mutagen, Solid-state fermentation

\begin{abstract}
This is an Open Access article that uses a funding model which does not charge readers or their institutions for access and distributed under the terms of the Creative Commons Attribution License (http://creativecommons.org/licenses/by/4.0) and the Budapest Open Access Initiative (http://www.budapestopenaccessinitiative.org/read), which permit unrestricted use, distribution, and reproduction in any medium, provided the original work is properly credited.
\end{abstract}

Tropical Journal of Pharmaceutical Research is indexed by Science Citation Index (SciSearch), Scopus, International Pharmaceutical Abstract, Chemical Abstracts, Embase, Index Copernicus, EBSCO, African Index Medicus, JournalSeek, Journal Citation Reports/Science Edition, Directory of Open Access Journals (DOAJ), African Journal Online, Bioline International, Open-J-Gate and Pharmacy Abstracts

\section{INTRODUCTION}

Butyric acid is an ill-smelling, 4-carbon, short chain fatty acid, $\mathrm{CH}_{3} \mathrm{CH}_{2} \mathrm{CH}_{2} \mathrm{COOH}$, and is an important solvent, polymer, and chemical compound used in the pharmaceutical, food, and chemical industries and is extensively used in thermoplastics. As a raw material, it is used to produce the biodegradable polymer $\beta$ - hydroxybutyrate [1]. It is also used in the treatment of colon cancer and as an energy source for the human body [2], and butyric acid esters give tropical fruits and dairy products their flavors $[3,4]$. Currently, there is great interest in using butyric acid as a precursor to biofuels.

On a commercial scale, butyric acid is produced through an oxy-fuel combustion process with 
petrochemicals as substrates [5]. The manufacturing of renewable chemicals by microbes has been stimulated by increases in oil prices, petrochemical industry environmental pollution, and consumer interest in the inclusion of natural ingredients in cosmetics, foods, and pharmaceuticals [6-10]. Although numerous Gram-positive obligate anaerobes, such as Clostridium spp. and Butyrivibrio fibrisolnes, produce significant amounts of butyric acid during fermentation [11], Clostridium strains are favored in industry because of their higher outputs and final-product concentrations [12]. Clostridium tyrobutyricum is one of the most preferred strains due to its high and stable production of butyric acid [13-15].

The cost to produce butyric acid by fermentation depends on the cost of the substrate, and it is costly to use pure carbon sources as substrates. The use of economically feasible and renewable substrates, such as agricultural products, as substrates has been investigated [16]. Agroindustrial wastes that are produced in bulk during milling include rice polishings, wheat bran, and molasses.

This is the first study that utilized rice polishings for butyric acid production by solid-state fermentation (SSF). More common processes for butyrate production are batch, fed-batch, continuous, and cell-recycle fermentations, but SSF is more economical due to low water requirements, reduced downstream processing, and low stirring requirements [17].

Due to the interest in using butyric acid as a biofuel precursor, this study aimed to hyperproduce butyric acid by creating a stable $C$. tyrobutyricum mutant and by optimizing fermentation parameters.

\section{METHODS}

\section{Bacterial strain and medium}

The parent strain C. tyrobutyricum DSM 2637 (ATCC $25755 \mathrm{NCIB} 110635$ ) was procured from DSMZ, Germany. The organism was revived and maintained under anaerobic conditions on Reinforced Clostridial Medium (RCM) agar plates and slants.

\section{Random mutagenesis}

C. tyrobutyricum DSM 2637 was exposed to various physical and chemical mutagens to create a mutant with enhanced butyric acid production.

\section{UV irradiation}

One $\mathrm{mL}$ of a fresh $C$. tyrobutyricum culture was transferred to RCM agar plates, and the plates were exposed to UV irradiation (Model: Mineral light UVS-12, California, USA) for various amounts of time (10-60 min). By adjusting the distance between the UV lamp and the culture plate to $5.0 \mathrm{~cm}$, a death rate of $95 \%$ was achieved [18].

To avoid photostimulation, the UV irradiated cells were grown in the dark in an anaerobic chamber at $37^{\circ} \mathrm{C}$ for $48 \mathrm{~h}$, colonies were counted, survival curves were generated, and colonies were screened for butyric acid production [15].

\section{Nitrous acid (NA) treatment}

NA solutions of various concentrations were prepared by adding $0.9 \mathrm{~mL}$ of $0.1 \mathrm{M}$ acetate buffer $(\mathrm{pH} 6.8)$ to $0.1 \mathrm{~mL}$ of varying concentrations of sodium nitrite $(1,2,3,4$, or 5 $\mathrm{M})$. Cell pellets of freshly grown $18 \mathrm{~h}$ cultures of C. tyrobutyricum were washed with $0.2 \mathrm{M}$ phosphate buffer pH 7.0 and incubated with NA for various amounts of time $(20,40$, or $60 \mathrm{~min})$ at $37^{\circ} \mathrm{C}$ [19]. The cells were then centrifuged and the cell pellets were washed with phosphate buffer to remove traces of the mutagen.

After washing, the cell pellets were resuspended in $1 \mathrm{~mL}$ of $0.2 \mathrm{M}$ phosphate buffer $\mathrm{pH} 7.0$, and serial dilutions were prepared and spread onto RCM agar plates. The plates were incubated in an anaerobic chamber at $37^{\circ} \mathrm{C}$ for $48 \mathrm{~h}$, colonies were counted, and survival curves were generated. Plates with a death rate $>90 \%$ were selected and colonies were screened for butyric acid production [15].

\section{Ethidium bromide (EtBr) treatment}

Cell pellets of freshly grown $18 \mathrm{~h}$ cultures of $C$. tyrobutyricum were resuspended in $2 \mathrm{~mL}$ of saline solution and incubated with varying concentrations of ethidium bromide $(15,18,21$, 24,27 , or $30 \mathrm{mg} / \mathrm{mL}$ ) at $37^{\circ} \mathrm{C}$ for $1 \mathrm{~h}$. The cells were centrifuged at $10,000 \mathrm{rpm}$ for $5 \mathrm{~min}$, resuspended in $1 \mathrm{~mL}$ of $0.2 \mathrm{M}$ phosphate buffer $\mathrm{pH} 7.0$, and serial dilutions were prepared and spread onto RCM agar plates.

The plates were incubated in an anaerobic chamber at $37^{\circ} \mathrm{C}$ for $48 \mathrm{~h}$, colonies were counted, and survival curves were generated. Plates with a death rate $>90 \%$ were selected and colonies were screened for butyric acid production [15]. 
Fermentation of wild type and mutant $C$. tyrobutyricum

Single wild type and mutant $C$. tyrobutyricum colonies were transferred from fresh RCM agar plates to $250 \mathrm{~mL}$ Erlenmeyer flasks containing 50 $\mathrm{mL}$ of RCM broth and incubated at $37^{\circ} \mathrm{C}$ for $24 \mathrm{~h}$ with shaking at $200 \mathrm{rpm}$. The cultures were diluted to an $\mathrm{OD}_{600}$ of 0.6 with $\mathrm{RCM}$ medium, added to fermentation media, and incubated under anaerobic conditions at $37^{\circ} \mathrm{C}$ for $72 \mathrm{~h}$. The fermentation medium contained $0.25 \%(\mathrm{v} / \mathrm{w})$ $\mathrm{NaCl}, \quad 0.25 \% \quad \mathrm{CaCl}_{2}, \quad 0.3 \% \quad \mathrm{MgSO}_{4}, \quad 0.15 \%$ $\mathrm{KH}_{2} \mathrm{PO}_{4}, 0.5 \%$ corn steep liquor, and $2.5 \mathrm{~g}$ rice polishings at $\mathrm{pH} 6.0$.

\section{Optimization of parameters for butyric acid production}

To increase the butyric acid yield, various fermentation parameters were tested. The parameters tested included the substrate:water ratio $(10: 24-10: 44)$, the volume of the inoculum (1-3 $\mathrm{mL}$ ), incubation time (2-8 days), the $\mathrm{NaCl}$ concentration $(0.125-30 \%)$, the $\mathrm{CaCl}_{2}$ concentration $(0.125-0.30 \%)$, the $\mathrm{MgSO}_{4}$ concentration $(0.175-0.35 \%)$, the $\mathrm{KH}_{2} \mathrm{PO}_{4}$ concentration $(0.05-0.25 \%)$, the nitrogen:carbon ratio $(1: 10-1: 30)$, and the corn steep liquor concentration $(0.2-0.8 \%)$. These fermentations were performed in $250 \mathrm{~mL}$ Erlenmeyer flasks containing $11.5 \mathrm{~mL}$ of medium under anaerobic conditions at $37^{\circ} \mathrm{C}$. The variations were tested in triplicate and were expressed as averages.

\section{Quantification of butyric acid}

Quantification of butyric acid was carried out by the organic analysis method [20], which is based on the catalytic oxidation of butyric acid into diacetic acid, which gives a red color upon the addition of sodium nitroprusside. Five $\mathrm{mL}$ of a fermented liquor sample was shaken first with 5 $\mathrm{mL}$ of a hydrogen peroxide solution, then shaken with one $\mathrm{mL}$ of a $5 \%$ ferrous ammonium sulphate solution, followed by shaking with 10 $\mathrm{mL}$ of a $10 \%$ sulfuric acid solution. The mixture was heated for $5 \mathrm{~min}$ in a water bath at $68-70$ ${ }^{\circ} \mathrm{C}$. Then, six drops of $20 \%$ sodium hydroxide were added to the cooled mixture and the mixture was filtered. Three drops of a $20 \%$ sodium hydroxide solution, three drops of a $5 \%$ sodium nitroprusside solution, and $0.5 \mathrm{~mL}$ of acetic acid were added to $5 \mathrm{~mL}$ of filtrate. In the presence of butyric acid, a rosy red color is produced, which can be measured spectrophotometrically by the absorbance at 390 $\mathrm{nm}$. The Pearson correlation coefficient was used to evaluate the relationship between $\mathrm{OD}_{390}$ and butyric acid concentration and showed that there is a positive linear correlation between $\mathrm{OD}_{390}$ and butyric acid concentration.

\section{Statistical analysis}

Data were analyzed statistically using SPSS 16.0 software and were presented as mean \pm SD of three replicates Means were compared by OneWay ANOVA, descriptive analysis, and least significant difference (LSD). $P<0.05$ were considered significant.

\section{RESULTS}

\section{Effect of physical and chemical mutagens on wild type C. tyrobutyricum}

After exposing wild type $C$. tyrobutyricum to UV irradiation, NA, and ethidium bromide, colonies from plates with a $>90 \%$ death rate were selected. The survival curves for each mutagenesis treatment are shown (Figure 1A). Mutant strains were screened for increased

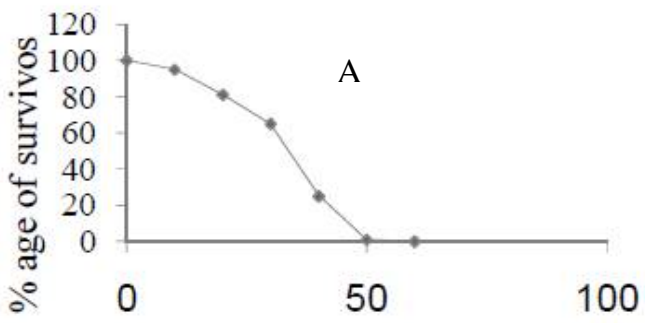

Exposure time (minutes)

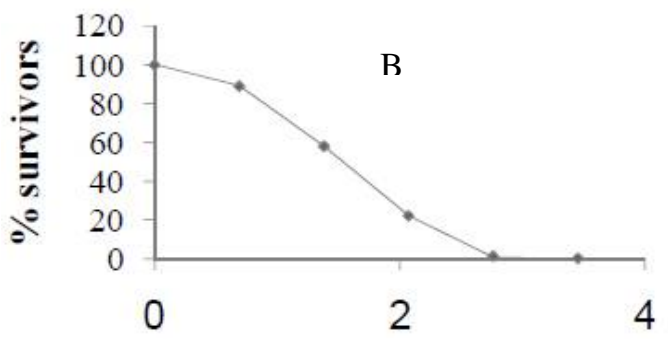

Nitrous acid concentration $(\mathrm{mg} / \mathrm{mL})$.

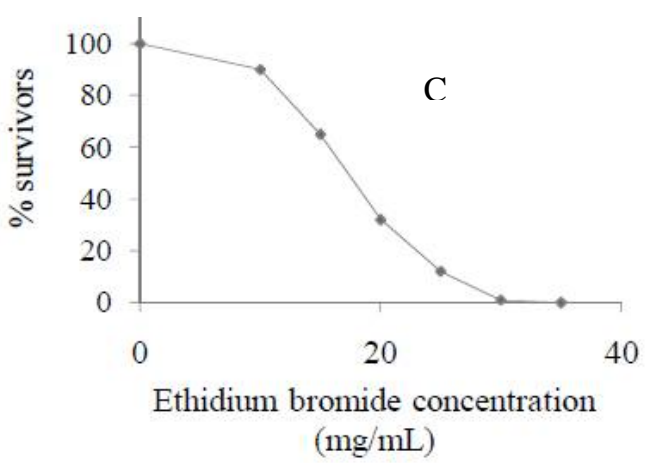

Figure 1: $C$. tyrobutyricum survival curves after treatment with physical and chemical mutagens: $(A)$ UV irradiation, (B) Nitrous acid, (C) Ethidium bromide 


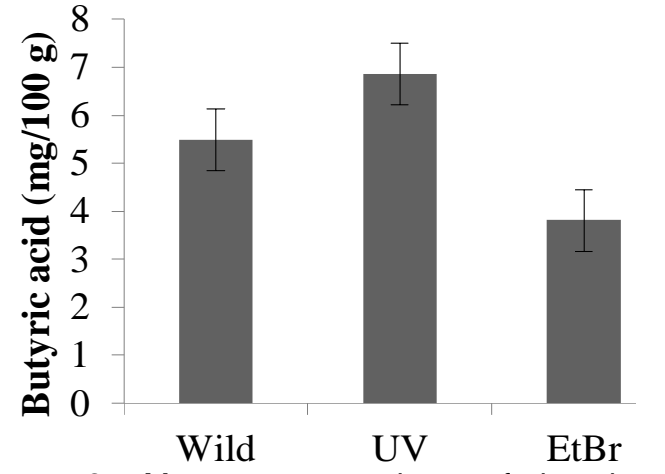

Figure 2: Mean concentrations of butyric acid produced by mutant $C$. tyrobutyricum strains. UV = Ultraviolet radiation-induced mutant; $\mathrm{EtBr}=$ Ethidium bromide-induced mutant; N.A = Nitrous acid-induced mutant

Table 1: Statistical analysis of mean concentrations of butyric acid produced by mutant $C$. tyrobutyricum strains

\begin{tabular}{llccc}
\hline $\begin{array}{l}\text { Yield } \\
\text { (mg/100 }\end{array}$ ) & \multicolumn{3}{c}{ Mutant } \\
\hline Butyr & $\begin{array}{c}\text { Wild } \\
\text { (control) }\end{array}$ & UV & EtBr & NA \\
ic & $5.48 \pm 0.27$ & $6.79 \pm 0.1$ & $3.85 \pm 0.0$ & $4.74 \pm 0.0$ \\
acid & $54^{\mathrm{b}}$ & $78^{\mathrm{a}}$ & $40^{\mathrm{d}}$ & $98^{\mathrm{c}}$ \\
\hline \multicolumn{4}{c}{${ }^{*}$ Means with different superscripts differ significantly $(p$} \\
$<0.05)$
\end{tabular}

butyric acid production using previously optimized fermentation conditions. The mutant strain generated with UV irradiation $\left(C . T^{U V}\right)$ produced $6.86 \mathrm{mg} / 100 \mathrm{~g}$ butyric acid, the mutant strain generated with ethidium bromide produced $3.81 \mathrm{mg} / 100 \mathrm{~g}$ butyric acid, and the mutant strain generated with NA produced $4.73 \mathrm{mg} / 100 \mathrm{~g}$ butyric acid, whereas the wild type strain produced $5.49 \mathrm{mg} / 100 \mathrm{~g}$ butyric acid (Figure 2, Table 1).

\section{Effect of various physiochemical parameters on butyric acid production}

We previously determined that rice polishings $(2.5 \mathrm{~g})$ are an optimal carbon source for wild type C. tyrobutyricum fermentation, thus we used rice polishings as the carbon source while optimizing other parameters, including the substrate:water ratio, the incubation period, and the inoculum volume, during SSF of the C. $T^{U V}$ mutant strain at $37^{\circ} \mathrm{C}$ and $\mathrm{pH}$ 6.0. Of the various substrate:water ratios, the 10:36 substrate:water ratio gave the highest butyric acid yield of $7.47 \mathrm{mg} / 100 \mathrm{~g}$ (Figure 3B), and of the various incubation periods, 3 days of incubation gave the highest butyric acid yield of $6.86 \mathrm{mg} / 100 \mathrm{~g}$ (Figure 3A). Of the various inoculum volumes tested, $2.5 \mathrm{ml}$ of inoculum gave the highest butyric acid yield of $7.69 \mathrm{mg} / 100 \mathrm{~g}$, whereas an increase in the inoculum to $3 \mathrm{~mL}$ reduced the butyric acid yield to $4.61 \mathrm{mg} / 100 \mathrm{~g}$ (Figure $3 \mathrm{C}$ ).
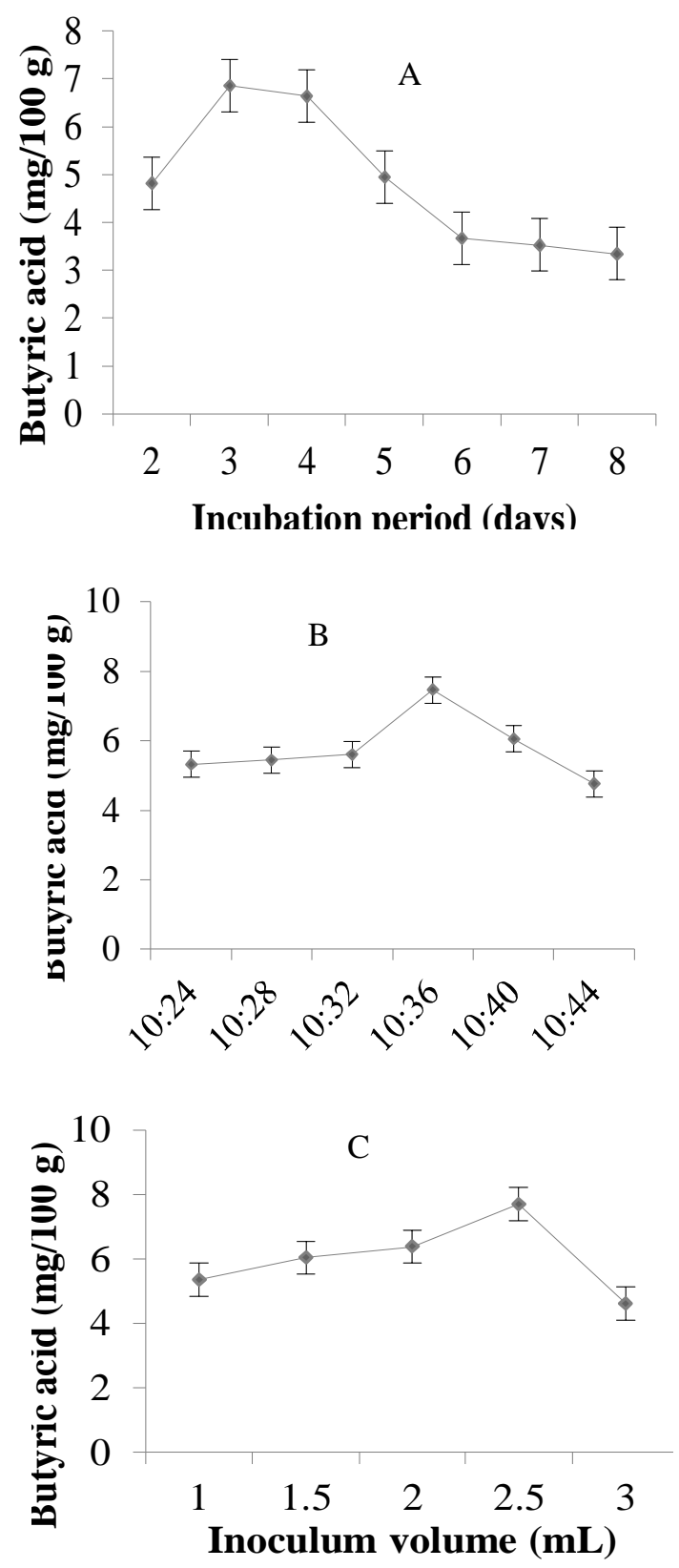

Figure 3: The effects of various parameters on butyric acid production during SSF of rice polishings by the mutant C. $T^{U V}$ at $\mathrm{pH} 6.0$ and $37^{\circ} \mathrm{C}$ : (A) Incubation period, (B) Substrate:water ratio, (C) Inoculum volume.

Various concentrations of $\mathrm{NaCl}, \mathrm{CaCl}_{2}, \mathrm{MgSO}_{4}$, and $\mathrm{KH}_{2} \mathrm{PO}_{4}$ were tested to determine optimal salt concentrations for the highest butyric acid yield during SSF of rice polishings by the mutant C. $T^{U V}$ at $\mathrm{pH} 6.0$ and $37^{\circ} \mathrm{C}$. The salt concentrations of $0.25 \% \quad(\mathrm{v} / \mathrm{w}) \quad \mathrm{NaCl}, \quad 0.25 \%$ $\mathrm{CaCl}_{2}, 0.3 \% \mathrm{MgSO}_{4}$, and $0.15 \% \mathrm{KH}_{2} \mathrm{PO}_{4}$ yielded the highest butyric acid concentrations of 8.8 $\mathrm{mg} / 100 \mathrm{~g}, 9.6 \mathrm{mg} / 100 \mathrm{~g}, 10.52 \mathrm{mg} / 100 \mathrm{~g}$, and $10.66 \mathrm{mg} / 100 \mathrm{~g}$, respectively (Figure $4 \mathrm{~A}-\mathrm{D}$ ). 

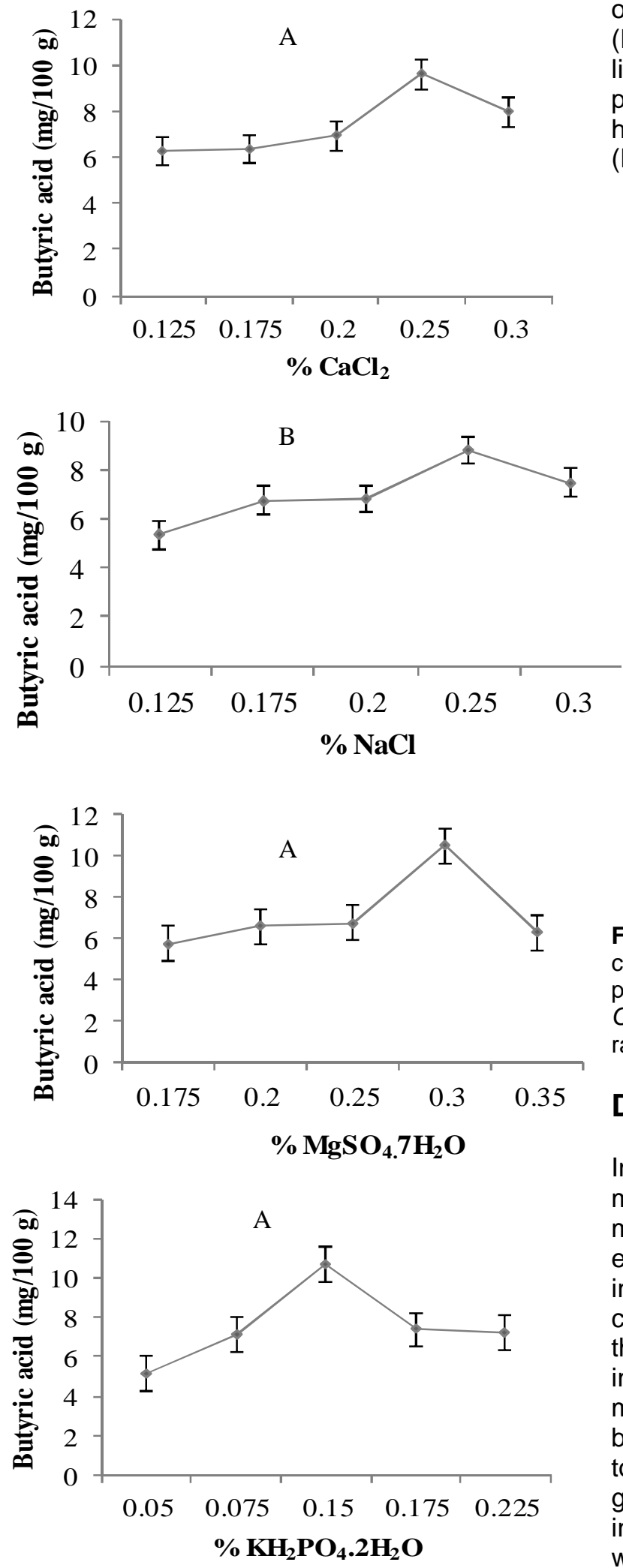

Figure 4: Effects of various salt concentrations on butyric acid production during SSF of rice polishings by mutant $C . T^{U V}$ at $\mathrm{pH} 6.0$ and $37^{\circ} \mathrm{C}$ : (A) $\mathrm{NaCl},(\mathrm{B})$ $\mathrm{CaCl}_{2},(\mathrm{C}) \mathrm{MgSO}_{4},(\mathrm{D}) \mathrm{KH}_{2} \mathrm{PO}_{4}$.

Various nitrogen:carbon ratios were investigated for maximum butyric acid production. The highest butyric acid yield of $11.63 \mathrm{mg} / 100 \mathrm{~g}$ was observed with a nitrogen:carbon ratio of 1:25 (Figure 5A). Various concentrations of corn steep liquor were also tested for maximum butyric acid production, and $0.6 \%$ corn steep liquor gave the highest butyric acid yield of $26.09 \mathrm{mg} / 100 \mathrm{~g}$ (Figure 5B).

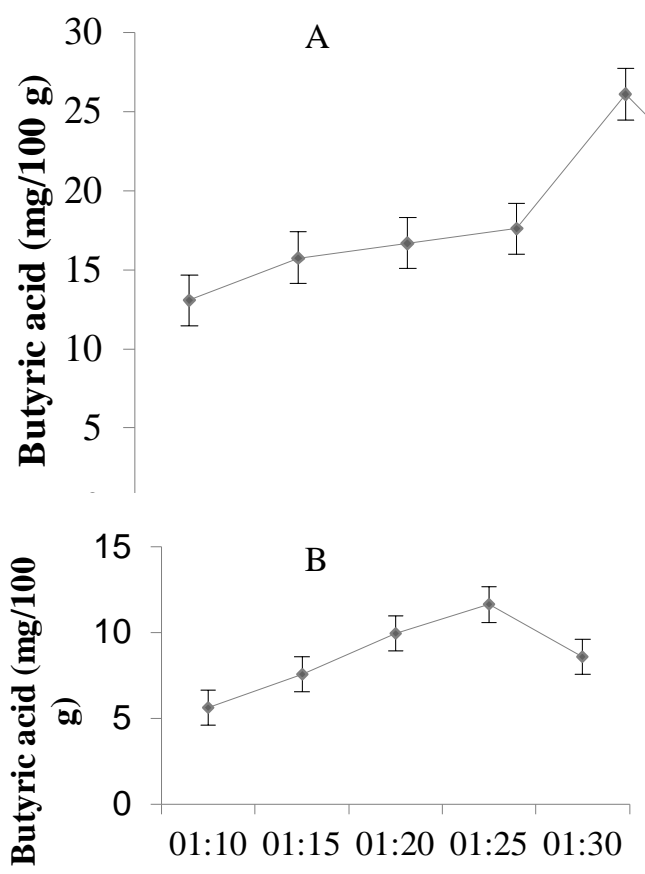

Nitrogen: carbon

Figure 5: Effects of the nitrogen:carbon ratio and the corn steep liquor concentration on butyric acid production during SSF of rice polishings by mutant C. $T^{U V}$ at $\mathrm{pH} 6.0$ and $37^{\circ} \mathrm{C}$ : (A) the nitrogen:carbon ratio, (B) corn steep liquor

\section{DISCUSSION}

In this study, we created three $C$. tyrobutyricum mutants by random mutagenesis, a UV-induced mutant, a nitrous acid-induced mutant, and an ethidium bromide-induced mutant. The UVinduced mutant produced significantly higher concentrations of butyric acid when compared to the ethidium bromide-induced and nitrous acidinduced mutants, and therefore the UV-induced mutant $C . T^{U V}$ was used in further studies. It has been reported that exposure of $C$. tyrobutyricum to heavy-ion irradiation with ${ }^{12} \mathrm{C}^{6+}$ led to the generation of a $C$. tyrobutyricum mutant that increased butyric acid production from $2.2 \mathrm{~g}$ in wild type to $3.3 \mathrm{~g}$ in the mutant [21]. The mutant C. $T^{U}$ significantly increased the butyric acid yield after 3 days of incubation and with a 10:36 substrate:water ratio. The volume of the inoculum generally affects the amount of product produced by fermentation. Previous studies found that $50 \mathrm{~mL}$ and $100 \mathrm{~mL}$ C. tyrobutyricum 
inoculum volumes increased butyric acid production by $5 \%(\mathrm{v} / \mathrm{v})$ to $34.2 \mathrm{~g} / \mathrm{L}$ and $3.87 \%$ to $4.3 \mathrm{~g}$, respectively $[10,12,22]$. In this investigation, a significantly higher concentration of butyric acid was produced with a $2.5 \%(\mathrm{v} / \mathrm{w}) C^{C} .^{U V}$ inoculum, whereas the maximum butyric acid yield with wild type $C$. tyrobutyricum was observed with a $2 \%(v / w)$ inoculum.

Butyric acid production may also be affected by the nutritional value of the medium. Rich media usually enhance butyric acid production. More butyric acid was produced by $C$. tyrobutyricum fermented in RCM than in Clostridial Growth Medium [8,23]. A medium containing $500 \mathrm{~g} / \mathrm{L}$ glucose, $25 \mathrm{~g} / \mathrm{L} \mathrm{MgSO}{ }_{4}, 1.3 \mathrm{~g} / \mathrm{L} \mathrm{MnSO}_{4}$, and 0.6 $\mathrm{g} / \mathrm{L} \mathrm{FeSO}_{4}$ has been recommended to increase butyric acid production [21]. It has also been shown that a nutrient formulation composed of $30 \mathrm{~g} / \mathrm{L}$ glucose, $5 \mathrm{~g} / \mathrm{L}$ yeast extract, $5 \mathrm{~g} / \mathrm{L}$ peptone, $3 \mathrm{~g} / \mathrm{L}\left(\mathrm{NH}_{4}\right)_{2} \mathrm{SO}_{4}, 0.6 \mathrm{~g} / \mathrm{L} \mathrm{MgSO}_{4}$, and $0.03 \mathrm{~g} / \mathrm{L} \mathrm{FeSO}_{4}$ increased butyric acid production [24]. Further, the addition of corn steep liquor with corn fiber hydrolysate as a substrate has been shown to increase the butyric acid yield [25]. In this study, we found a C. tyrobutyricum mutant strain that significantly increased butyric acid production 1.4-fold when compared to the wild type $C$. tyrobutyricum strain.

\section{CONCLUSION}

An SSF technique for butyric acid production using rice polishings as the substrate has been developed. The C.T $T^{U V}$ mutant increased butyric acid production to $26.09 \mathrm{mg} / 100 \mathrm{~g}$, which is 1.4 fold more than the butyric acid produced by the wild type parent strain, thus this simple and inexpensive method can be used for butyric acid production on a commercial scale.

\section{DECLARATIONS}

\section{Acknowledgement}

The authors would like to thank Dr. Masood Rabbani, Dr. Fareeha, Ms. Huma Mujahid, and the University Diagnostic Laboratory (UDL) for providing the facilities to perform the random mutagenesis procedures.

\section{Conflict of interest}

No conflict of interest is associated with this work.

\section{Contribution of authors}

We declare that this work was done by the authors named in this article and all liabilities pertaining to claims relating to the content of this article will be borne by the authors. Ms. Tasleem Akhtar, Dr. Abu Saeed Hashmi, Dr. Muhammad Tayyab, and Aftab Ahmed Anjum conceived and designed the study. Ms. Tasleem Akhtar collected and analyzed the data and wrote the manuscript. Dr. Shagufta Saeed assisted in the writing of the manuscript. All of the authors have read and approved the manuscript for publication.

\section{REFERENCES}

1. Lefranc $L$, Cie $E$. A process for the manufacture of butyric acid and other fatty acids with recovery of the gases of fermentation. Br Pat 1923; 186572.

2. Hara H. Physiological effects of short-chain fatty acid produced from prebiotics in the colon. Biosc Microflora 2002; 21: 35-42.

3. Centeno J, Tomillo A, Fenández FJ, Gaya E, Nunez $P$. Effect of wild strains of Lactococcus lactis on the volatile profile and the sensory characteristics of Ewes' raw milk cheese. J Dairy Sci 2002; 85: 3164-3172.

4. Watson R, Wright CJ, Mcburney T, Taylor AJ, Linforth RST. Influence of harvest data and light integral on the development of strawberry flavor compounds. J Exp Bot 2002; 53: 2121-2129.

5. Mascal M. Chemicals from biobutanol: technologies and markets. Biofuel Bioprod Bior 2012; 6:483-493.

6. Tan TW, Shang F, Zhang $X$. Current development of biorefinery in china. Biotechnol Adv 2010; 28: 543-555.

7. Timothy $D B$, Mark A, Elizabeth $M H$, Rahul S. The emerging role for bacteria in lignin degradation and bioproduct formation. Curr Opin Biotechnol 2010; 22: 1-7.

8. Dwidar M, Park JY, Mitchell RJ, Sang RI. The future of butyric acid in industry. The Scientific World $J$ 2012; Volume 2012, Article ID 471417, 9 pages doi:10.1100/2012/471417

9. Liu S, Bischoff KM, Leathers TD, Qureshi N, Rich, JO, Hughes SR. Butyric acid from anaerobic fermentation of lignocellulosic biomass hydrolysates by Clostridium tyrobutyricum strain RPT-4213. Bioresource Technol 2013; 143: 322-329.

10. Zhang $C$, Yang $H$, Yang $F$, Ma Y. Current progress on butyric acid production by fermentation. Curr Microbiol 2009; 59: 656-663.

11. Liu $X$, Zhu $Y$, Yang $S$. Butyric acid and hydrogen production by Clostridium tyrobutyricum ATCC 25755 and mutants. Enzy \& Micro Tech 2006; 38: 521-528.

12. Najafpour GD. Immobilization of microbial cells for the production of organic acid and ethanol. Biochem Eng \& Biotech 2006; 8:199-227.

13. Song $H$, Eom $M H$, Lee S, Lee J, Cho JH, Seung $D$. Modeling of batch experimental kinetics and application to fed-batch fermentation of Clostridium tyrobutyricum for enhanced butyric acid production. Biochem Eng $J$ 2010; 53: 71-76.

Trop J Pharm Res, July 2018; 17(7): 1240 
14. Fayolle F, Marchal R, Ballerini D. Effect of controlled substrate feeding on butyric acid production by Clostridium tyrobutyrium. $J$ of Industrial Microbiol 1990; 6: 179-183.

15. He GQ, Kong Q, Chen $Q H$, Ruan H. Batch and fed-batch production of butyric acid by Clostridium butyricum ZJUCB. J Zhejiang University 2005; 6: 1076-1080

16. Amin M, Bhatti HN, Zuber M, Bhatti IA, Asgher M. J Anim PI Sci 2014; 24: 1430-1437.

17. Pandey A. Solid state fermentation. Biochem Engin J 2003; 13: 81-88.

18. Azin DA, Norooz RF. Effect of chemicals on the improved gluconate productivity by an Aspergillus niger strain. Appl Biochem Biotechnol 2001; 61: 393-397.

19. Mishra L, Vernekar M, Harmalkar M. Effect of UV and nitrous acid treatment on production of xylanase enzyme by Acinetobacter sp. Int J Curr Microbiol Appl Sci 2014; 3: 45-53.

20. Deniges G. Detection and estimation of butyric acid. Ann Chim Analy Appl 1918; 23: 27-31.
21. Zhou X, Hong LU, Xue H, Zhi J, Rong X, Rong Z, Liang $W$, Wen $Y$, Jianping $L$. Radiation induces acid tolerance of Clostridium tyrobutyricum and enhances bioproduction of butyric acid through a metabolic switch. Biotechnol for Bio 2014; 7: 22.

22. Zhang $C$, Yang $H$, Yang $F, M a Y$. Current progress on butyric acid production by fermentation. Curr Microbiol 2009; 59: 656-663.

23. Mitchell WJ. Biology and physiology. In: Clostridia, Biotechnology and medical applications, eds. Bahl $H$ and Dürre P. Wiley-VCH. Weinheim 2001; 49-104.

24. Jiang L, Wang J, Liang S, Wang $X$, Cen $P, X u Z$. Production of butyric acid from glucose and xylose with immobilized cells of Clostridium tyrobutyricum in a fibrous-bed bioreactor. App. Biochem \& Biotechnol 2010; 16: 350-359.

25. Zhu Y, Yang ST. Adaptation of Clostridium tyrobutylicum for enhanced tolerance to butyric acid in a fibrous-bed bioreactor. Biotech Prog 2003; 19:365-372. 